E3S Web of Conferences 1, 11010 (2013)

DOI: $10.1051 / \mathrm{e} 3$ sconf/20130111010

(c) Owned by the authors, published by EDP Sciences, 2013

\title{
Ultrastructural damage in tomato plants exposed to chromium III
}

\author{
P. A. Mangabeira ${ }^{1}$, A. -A. F. de Almeida ${ }^{2}$, V. L. Souza ${ }^{3}$, A. J. dos Santos Júnior ${ }^{4}$, D. C. Silva ${ }^{5}$, R. M. de Jesus ${ }^{6}$ \\ ${ }^{1}$ Universidade Estadual de Santa Cruz, Km 16 Rodovia Ilhéus Itabuna. Ilhéus Bahia Brazil. paomangabeira@uesc.br \\ ${ }^{2}$ Universidade Estadual de Santa Cruz, Km 16 Rodovia Ilhéus Itabuna. Ilhéus Bahia Brazil. alexalan@gmail.com \\ ${ }^{3}$ Universidade Estadual de Santa Cruz, Km 16 Rodovia Ilhéus Itabuna. Ilhéus Bahia Brazil., vlsouza@uesc.br \\ ${ }^{4}$ Universidade Estadual de Santa Cruz, Km 16 Rodovia Ilhéus Itabuna. Ilhéus Bahia Brazil. orquibio@yahoo.com.br \\ ${ }^{5}$ Universidade Estadual de Santa Cruz, Km 16 Rodovia Ilhéus Itabuna. Ilhéus Bahia Brazil. delmira@uesc.br \\ ${ }^{6}$ Universidade Estadual de Santa Cruz, Km 16 Rodovia Ilhéus Itabuna. Ilhéus Bahia Brazil. raildo@uesc.br
}

\begin{abstract}
The study aimed to investigate the short-term effects of $\mathrm{Cr}$ on the ultrastructure of root, stem and leaf cells of tomato plants (Solanum lycopersicum L.), and to verify the compartmentalization of the transition metal. Tomato seedlings were grown in an environmental chamber maintained at $25 \pm 1^{\circ} \mathrm{C}$, with relative humidity of $70 \%$ and a $12 \mathrm{~h}$ photoperiod, in full-strength nutrient solution containing 25 or $50 \mathrm{mg} \mathrm{L}^{-1}$ of $\mathrm{Cr}(\mathrm{III})$, while control plants were cultured in the absence of Cr. An electron probe X-ray microanalyzer equipped with a wavelength dispersive spectrometer was used in association with transmission electron microscopy in order to localize $\mathrm{Cr}$ deposits. In tomato roots $\mathrm{Cr}$ deposits were concentrated mainly in the cell walls, while in stems and leaves the deposits could be observed in the cells walls as well as in vacuoles, suggesting that these compartments act as barriers against metal phytotoxicity. Plants exposed to $\mathrm{Cr}$ presented leaves containing abnormally shaped chloroplasts, with reduced numbers of grana and atypical thylakoids, whereas the mitochondria presented reduced numbers of cristae. These $\mathrm{Cr}$-induced alterations result in the diminution of photosynthetic and respiratory activities with harmful consequences to plant health. The microanalytical methods employed in this study have shed new light onto the possible causes of $\mathrm{Cr}$ phytotoxicity. Such knowledge is valuable in understanding the mechanisms employed by plants to circumvent the uptake and transport of potentially toxic metals.
\end{abstract}

Key words: Microanalysis, Chromium toxicity, Cellular damage, Abnormal chloroplast, Abnormal mitochondria

\section{Introduction}

The consumption of crop plants represents an important route for the transport of potentially toxic elements from the soil to man, since trace metals accumulated in plant tissues can intoxicate animals and humans before any phytotoxic effects become evident. The intake of heavy metals by organisms in general can produce either direct toxicity, expressed in the form of pathologies, or indirect toxicity resulting from the bioaccumulation of metal transferred from different trophic levels. In plants, heavy metal toxicity can lead to a reduction in photosynthesis and, consequently, in plant growth (Maine et al., 2004; Choudhury and Panda, 2005).

Scanning electron microscopic (SEM) analysis of plant tissues has been employed to identify
$\mathrm{Cr}$ (III)-organic complexes typically in the form of chromium oxalate crystals deposited on the leaf surface (Lytle et al., 1998). Modern electron probe X-ray microanalysis (EPMA) represents a powerful tool for the qualitative and quantitative analysis of elements within regions as small as a few $\mu \mathrm{m}^{3}$. Moreover, coupling the microanalyzer with a wavelength dispersive spectrometer (WDS) allows the unambiguous identification of most elements in the periodical table (except for hydrogen, helium and lithium).

The aim of the present study was to enhance our understanding of the short-term effects of $\mathrm{Cr}$ (III) on the ultrastructure of roots, stems and leaves, and to verify the compartmentalization of the element within the tissues. To this end, we have employed EPMA/WDS microprobe technology in association with transmission electron 
microscopy (TEM) at magnifications up to $50000 \mathrm{X}$ to detect $\mathrm{Cr}$ (III) in insoluble and bound forms in roots, stems and leaves of tomato plants.

\section{Materials and Methods}

The growth experiments were carried out in an environmental chamber maintained at $25 \pm 1{ }^{\circ} \mathrm{C}$, with relative humidity of $70 \%$ and a $12 \mathrm{~h}$ photoperiod of white light (Osram HQI-E lamp; $400 \mathrm{~W}$ ) with a photon fluence rate of $500 \mu \mathrm{mol} \mathrm{m} \mathrm{m}^{-2} \mathrm{~s}^{-1}$, as measured at the top of the plant canopy. Aeration for the culture solutions was provided by filtered compressed air.

Seeds of tomato (Solanum lycopersicum L.) were germinated in acid washed sand for 15 days. Seedlings were transferred to $1 \mathrm{~L}$ jars and grown hydroponically in half strength nutrient solution (composition according to Moral et al., 1996) at pH 5.5 for 7 days, and subsequently in full-strength nutrient solution in the absence (control plants) or presence (experimental plants) of $\mathrm{CrCl}_{3} \cdot 6 \mathrm{H}_{2} \mathrm{O}$ at concentrations of 25 or $50 \mathrm{mg} \mathrm{L}^{-1}$. The hydroponic medium was changed weekly. Four replicates of the control and the two sets of experimental plants were placed randomly around the growth chamber.

Root, stem and leaf samples were collected following 30 days of treatment with $\mathrm{Cr}$ and at equivalent times for controls. Samples were cut and fixed for $2 \mathrm{~h}$ at room temperature in a solution of $3 \%$ glutaraldehyde in sodium cacodylate buffer $(0.1 \mathrm{M} ; \mathrm{pH} 7.2)$. After three washes with cacodylate buffer, the samples were postfixed for $2 \mathrm{~h}$ in a solution of osmium tetroxide $\left(\mathrm{OsO}_{4}\right.$; $1 \% \mathrm{w} / \mathrm{v})$ in cacodylate buffer, dehydrated with serial concentrations of ethyl alcohol and embedded in Spurr's low-viscosity epoxy resin (Spurr, 1969). Ultra-thin (60-70 nm) sections were cut on a Reichert-Jung (Leica) Ultracut E ultramicrotome with a diamond blade and examined under a Philips model 220 TEM microscope operating at $60 \mathrm{kV}$ and providing magnifications of up to $50000 X$.

Unstained ultra-thin sections were deposited on copper grids and coated with carbon prior to analysis. Analyses were carried out using a CAMECA (Camebax) electron probe microanalyser (Courbevoie, France) equipped with a WDS system with three different crystals types, namely, thallium acid phthalate (TAP), pentaerythritol (PET) and lithium fluoride (LIF). The high resolving power of the WDS eliminated potential interference between $\mathrm{Cr}$ and $\mathrm{Os}$ (employed in $\mathrm{OsO}_{4}$ staining). The $\mathrm{K}_{\alpha}$ lines of phosphorus (P) and $\mathrm{Cr}$ were detected with PET, while the L $\gamma$ line of Os was detected with TAP. The EPMA/WDS was adapted to TEM and operated under the following conditions: accelerating voltage $45 \mathrm{kV}$, probe diameter $0.5 \mu \mathrm{m}$ and probe current $50 \mathrm{nA}$. Elements present under the microprobe at concentrations greater than $100 \mu \mathrm{g} / \mathrm{g}$ could be analyzed.

\section{Results and Discussion}

$\mathrm{Cr}$ deposits were present in the symplast of cells in the cortical parenchyma of roots from plants that had been exposed to $\mathrm{Cr}$ at $25 \mathrm{mg} \mathrm{L}^{-1}$ (Fig. 1B). Inclusions of $\mathrm{Cr}$ could also be detected in the vacuoles of parenchyma cells associated with secondary root xylem in plants exposed to $\mathrm{Cr}$ at $50 \mathrm{mg} \mathrm{L}^{-1}$ (Figs. 1A) and at $25 \mathrm{mg} \mathrm{L}^{-1}$, whereas no $\mathrm{Cr}$ deposits were observed in the cell walls. Dense $\mathrm{Cr}$ inclusions were present in the symplast of parenchyma cells of roots of plants that had been exposed to $\mathrm{Cr}$ at $50 \mathrm{mg} \mathrm{L}^{-1}$. In each case, the presence of $\mathrm{Cr}$ was confirmed by spectral analysis (shown as inserts in the respective figures)

The leaves of control plants presented chloroplasts of normal shape with smooth membrane envelopes. In contrast, leaves from plants exposed to $\mathrm{Cr}$ at 25 or $50 \mathrm{mg}$ $\mathrm{L}^{-1}$ contained chloroplasts with various structural alterations including envelopes exhibiting jagged outer membranes (Fig. 1B), abundance of starch granules and atypical arrangements and reduced numbers of thylakoid membranes (Fig. 1C). Moreover, the leaves of these plants presented uncharacteristic filamentous chloroplasts containing numerous membranous vesicles (Fig. 8E).

In the present study, EPMA/WDS/TEM analysis revealed $\mathrm{Cr}$ inclusions in the vacuoles of the parenchyma cells associated with the root xylem. Lutge (1983) has shown that parenchyma cells adjacent to vessel elements perform a secretory function and play a role in the transport of metals to the aerial parts. As demonstrated herein, the parenchyma cells of tomato roots are rich in mitochondria, indicating a strong ATPase activity that enables the accumulation of transported metals against the electrochemical gradient.

The presence of $\mathrm{Cr}$ within the dense insoluble material observed in the parenchyma of leaf protoplasts close to the xylem was confirmed by analysis of the $\mathrm{X}$-ray spectra. It is possible that the $\mathrm{Cr}$ is linked to the cysteine groups of phytochelatins, thus immobilizing the metal and reducing its action on the cellular structures (Choudhury and Panda, 2005).

In the case of tomato plants, the cells walls were found to be the preferential sites of $\mathrm{Cr}$ deposition. The cell wall comprises cellulose and hemicellulose microfibrils embedded in a pectin-rich matrix, and the structured layers present a high capacity for cation exchange. This cell wall property has been amply demonstrated in plants of Leersia hexandra Swartz (Liu et al., 2009) that had been exposed to $\mathrm{Cr}$ at $60 \mathrm{mg} \mathrm{L}^{-1}$, where $83.2 \%$ of the metal absorbed was detected in the cell walls, of which $57.5 \%$ was found to be present in the leaves.

Chloroplasts in the leaves of plants that had been exposed to $\mathrm{Cr}$ at $25 \mathrm{mg} \mathrm{L}^{-1}$ exhibited reductions in the number of grana and excessive accumulations of starch granules. Such findings are similar to those reported for Spirodela polyrhiza (Appenroth et al., 2003). According to Rauser and Samarakon (1980), $\mathrm{Cr}$ reduces carbohydrate flow in the phloem, an effect that may be mediated by the inhibition of transport of sucrose from the inside to the outside of the chloroplast envelope. Poschenrider et al. (1991) suggested that this phenomenon might be associated with an increase of 
biologically active iron in solution.

The application of EPMA/WDS microprobe technology has provided insights into the effects of $\mathrm{Cr}$ on cellular and subcellular structures that cannot be acquired using other methodologies. Moreover, microprobe analysis affords semi-quantitative information that enables the concentration of specific elements to be evaluated, while the high resolving power of WDS eliminates potential interference between $\mathrm{Cr}$ and the $\mathrm{Os}$ employed in staining.

\section{Conclusion}
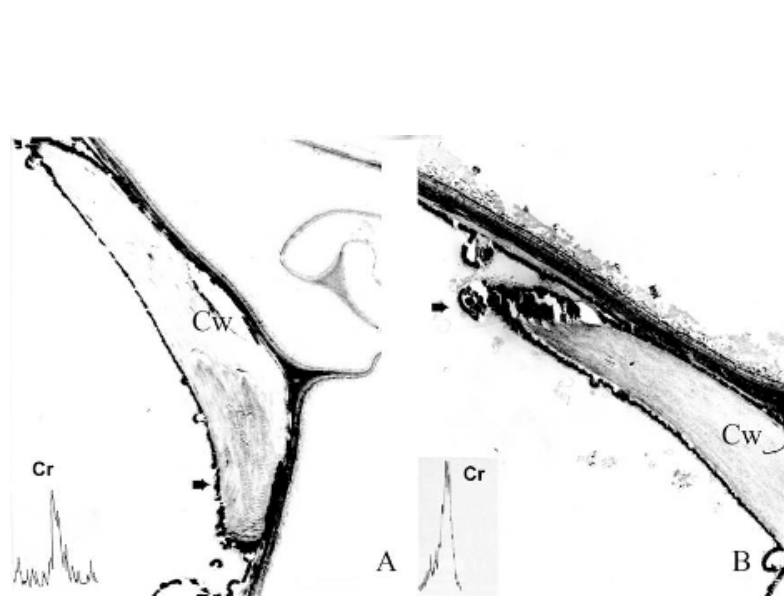

The microanalytical methods employed in this study have shed new light onto the possible causes of metal phytotoxicity. The knowledge regarding the mechanisms used by plants to circumvent the uptake and transport of metals is essential in the understanding of plant resistance and, consequently, in the genetic engineering of varieties exhibiting improved phytoremediation abilities or those in which the absorption and accumulation of metals have been reduced to a minimum.

Fig. 1. A, B and C: A-B Cell wall of tomato plant. C-D-E. Chloroplast of tomato plant exposed to chromium.

\section{Acknowledgements}

The authors thank the financial supports providing from CNPq Conselho nacional de Desenvolvimento Científico e Tecnológico - Brazil).

\section{References}

Appenroth, K.J., Keresztes, A., Sarvari, E., Jaglarz, A., Fischer,W., 2003. Multiple effects of chromate on Spirodela polyrhiza: Electron microscopy and biochemical investigations. Plant Biol. 5, 315-323.

Choudhury, S., Panda, S.K., 2005. Toxic effects, oxidative stress and ultrastructural changes in the moss Taxithelium nepalense (Schwaegr.) Broth. under chromium and lead phytotoxicity. Water Air Soil Pollut. 167, 73-90.

Maine, M.A., Suñé, N.L., Lagger, S.C., 2004. Chromium bioaccumulation: comparison of the capacity of two floating aquatic macrophytes. Water Res. 38, 1494-1501.

Moral, R., Gomez, I., Pedreno, J.N., Mataix, J., 1996. Absorption of chromium and effects on micronutrient content in tomato plant (Lycopersicum esculentum Mill.). Agrochimica 11, 138-145.

Liu, J., Duan, C.Q., Zhang, X.H., Zhu, Y.N., Hu, C., 2009. Subcellular distribution of chromium in accumulating plant Leersia hexandra Swartz. Plant Soil 322, 187-195.

Lutge, U., 1983. Import and export of mineral nutrient in plant roots. In: Lauchli, A., Bieleski, R.L. (Eds), Encyclopédia of Plant Physiology (New Series), Volume 15A - Inorganic Plant Nutrition. Springer-Verlag, Berlin, pp. 181-211.

Rauser, W.E., Samarakon, A.B., 1980. Vein loading in seedlings of Phaseolus vulgaris exposed to excess cobalt, nickel and zinc. Plant Physiol. 65, 578-583. 